\title{
A Graphical User Interface for dynamics and feedback control studies: focus on chemical reactors
}

\author{
Bartolomeo Cosenza, Michele Miccio
}

\begin{abstract}
A program in MATLAB's Graphical User Interface (GUI) is developed to study dynamic behavior and traditional PID control of simple nonlinear reference systems, such as a discontinuous batch reactor and a continuous bioreactor. Once either system is selected by the GUI user, the program underlying the GUI provides simulation for various values of the input variables in an easy and intuitive way, showing a strong educational value. It allows exploration of simulation, modeling and control for users without theoretical knowledge.
\end{abstract}

Keywords-Batch reactor, bioreactor, simulation, non-linear systems, dynamics, education, Graphical User Interface, MATLAB, PID control

\section{INTRODUCTION}

Simulation is a technical discipline the target of which is the imitation of operations of a real system. Simulation requires something to represent the key characteristics of the selected physical system, i.e. a model. If the model represents the selected system, its simulation well represents its operation over time. In chemical and process industry, the study of dynamics is very useful to monitor, control and optimize many processes. Usually, simulation allows to predict the time evolution of output variables of a process model, once the input variables are known. Non-linear systems have been focused since a few decades as theoretical, but realistic means to describe, design, simulate plants and their control systems in chemical, biochemical, food and other engineering areas [1],[2],[3]. The underlying mathematical models are also nonlinear and consist of a set of ordinary or partial differential equations.

Some simple process units, which represent a reference in chemical engineering studies and applications, are actually non-linear systems, like the case of authothermal and adiabatic reactors, either batch or fed-batch or continuous. The issue of their automatic process control, although widely investigated in research and teaching literature, still remains a live one. Chemical reactor design and control was covered by Luyben [3] [4]; more recently, a continuity diagram analysis at open as well as closed loop was developed by Cosenza et al. [5] to improve the operability of a reactor; a nonlinear model predictive control of a batch fluidized bed dryer for pharmaceutical particles was proposed by Gagnon et al. [6]; Holmqvist and Magnusson developed an open-loop optimal control of batch chromatographic separation processes using direct collocation methods [7]; an optimal control of batch cooling crystallizers by using genetic algorithm was proposed by Amini et al [8]; Wu et al. improved design of constrained model predictive tracking control for batch processes against unknown uncertainties [9], Yuan et al. [10] realized an optimal control of a batch fermentation process with nonlinear timedelay and free terminal time and cost sensitivity constraint. Dieulot proposed a productivity signal feedback controller for continuous bioreactors [11]; Imtiaz et al. [12] proposed a bioreactor profile control by a nonlinear autoregressive moving average neuro and two degree of freedom PID controllers; Gerardo et al. [13] suggested an extremum seeking approach via variable-structure control for fed-batch bioreactors with uncertain grow rate; an estimation problem of a class of continuous bioreactors with unknown input was advanced by Moreno and Alvarez [14]; advanced control strategies for bioreactors were proposed by Pörtner et al [15]; a bioreactor temperature control using modified fractional order IMC-PID was used by Pachauri et al., for ethanol production [16].

The attention and progress that non-linear systems have faced in modern scientific research and textbook production is not paralleled by a similar growth in software tools targeting their easier comprehension and a student-tailored application. Therefore, in this paper we will focus on a batch discontinuous reactor and a continuous bioreactor as dynamical systems, which are chosen as reference systems and simulated in the continuous time domain within a simple Graphical User Interface environment.

Department of Industrial Engineering

University of Salerno

Fisciano (SA), Italy

Cosenza Bartolomeo

Miccio Michele

\section{MATLAB GUI OF CHEMICAL REACTORS}

A GUI (Graphical User Interface) allows an approach to the study of chemical processes dynamics in a way that is easy, intuitive and very useful didactically. A GUI provides "tip-andclick" control over software applications, eliminating the need to learn a language or to type commands to execute the application. The Matlab GUIDE (i.e., GUI Development Environment) provides simple tools to design user interfaces for custom apps. GUIDE automatically generates the MATLAB code [17], [18].

With the GUI presently developed by the authors, it is possible to choose the type of chemical reactor (i.e., discontinuous or continuous) and to start simulations at open loop and with feedback control [19], [20], [21], [22], [23], [24], [25].

The Matlab code comes with the interface shown in the Figure 1, where it is possible to select either a batch reactor or a 
Proc. of the Fifth International Conference on Advances in Civil, Structural and Environmental Engineering - ACSEE 2017. Copyright $\odot$ Institute of Research Engineers and Doctors. All rights reserved.

ISBN: 978-1-63248-122-1 doi: 10.15224/ 978-1-63248-122-1-32

continuous bioreactor.

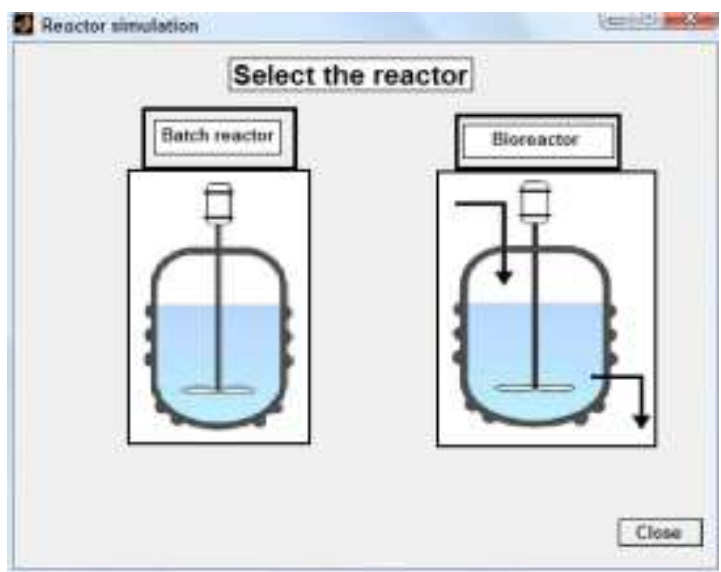

Fig. 1. Main GUI interface to select batch reactor or bioreactor.

Once chosen the reactor, it is possible to access a graphical window (see Figure 2 and 3) where one can enter values of some system parameters and input variables.
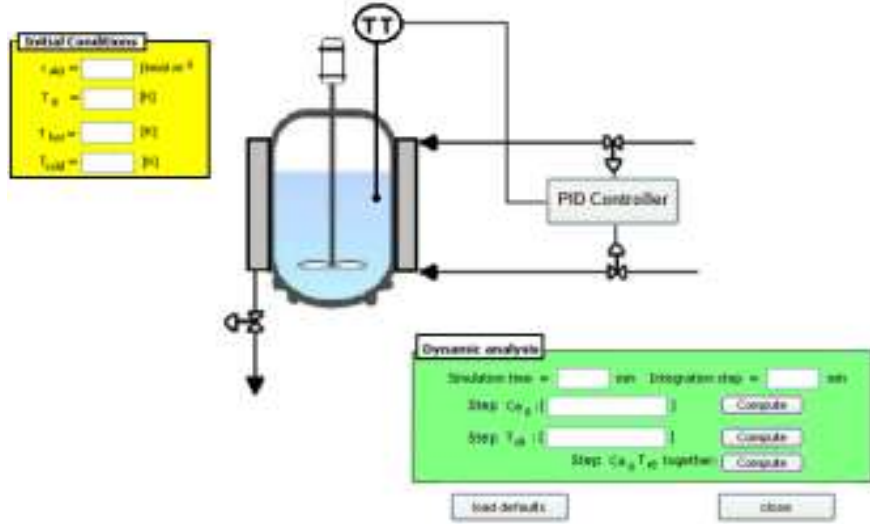

Fig. 2. Batch reactor GUI

\section{Batch reactor}

The batch reactor is widely used for a variety of process operations and consists of a tank with an agitator and integral heating/cooling system, Liquids and solids are usually fed via connections in the top cover of the reactor. Vapors and gases also discharge through connections in the top. Liquids are usually discharged from the bottom [3] [4]. The batch reactor model here used by the authors [4] is described by the following simple ODE system:

Mass Balance:

$$
\frac{d\left[C_{a}\right]}{d t}=-K C_{a}
$$

\section{Energy Balance:}

$$
\begin{aligned}
& \frac{d\left[T_{r}\right]}{d t}=\frac{-\lambda K C_{a}}{\rho c_{p}}-\frac{U A_{j}\left(T_{r}-T_{j}\right)}{V_{r} \rho c_{p}} \\
& \frac{d\left[T_{j}\right]}{d t}=\frac{\left(F_{h o t} h_{h o t}+F_{\text {cold }} T_{\text {cold }}\right)}{V_{j}}-\frac{\left(F_{h o t}+F_{\text {cold }}\right) T_{j}}{V_{j}}+\frac{U A_{j}\left(T_{r}-T_{j}\right)}{V_{j} \rho_{j} c_{j}}
\end{aligned}
$$

\section{Bioreactor}

It is well known that biochemical reactors are used to produce a large number of intermediate and final products, including pharmaceuticals, food, and beverages [3].

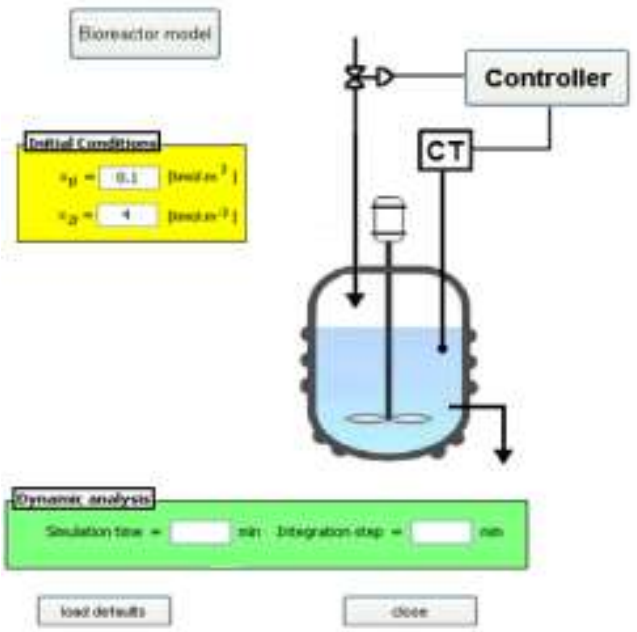

Fig. 3. Bioreactor GUI.

The considered bioreactor is a perfectly stirred continuous system as described by the following simple ODE system [1]: Mass Balance:

$$
\begin{aligned}
& \frac{d\left[x_{1}\right]}{d t}=(\mu-D) x_{1} \\
& \frac{d\left[x_{2}\right]}{d t}=D\left(x_{2 f}-x_{2}\right)-\frac{\mu x_{1}}{Y}
\end{aligned}
$$

with $\mu$ described by the substrate inhibition kinetic model:

$$
\mu=\frac{\mu_{\max } x_{2}}{k_{m}+x_{2}+k_{1} x_{2}^{2}}
$$

In Table 1 symbol, variable, parameter values and units are reported for bioreactor model.

Only two components are considered in this model: biomass and substrate (see Figure 4); the energy balance is overlooked. The biomass consists of cells that consume the substrate. An example is fermentation, where cells consume sugar and produce alcohol. The process exhibits some dynamical properties that make it difficult to operate, and therefore the design of a high-performance controller is necessary for its safe operation [5]. 
Proc. of the Fifth International Conference on Advances in Civil, Structural and Environmental Engineering - ACSEE 2017. Copyright $\odot$ Institute of Research Engineers and Doctors. All rights reserved.

ISBN: 978-1-63248-122-1 doi: 10.15224/ 978-1-63248-122-1-32

TABLE 1 - BioREACTOR SyMbols, VARIABLES AND PARAMETERS

\begin{tabular}{|l|l|l|l|}
\hline Symbol & Variable or parameter & Value & Units \\
\hline$x_{1}$ & Biomass & & $\mathrm{kg} / \mathrm{m}^{3}$ \\
\hline$x_{2}$ & Substrate & & $\mathrm{kg} / \mathrm{m}^{3}$ \\
\hline$\mu$ & Growth rate & & $\mathrm{h}^{-1}$ \\
\hline$\mu_{\max }$ & Maximal growth rate & 0.53 & $\mathrm{~h}^{-1}$ \\
\hline$k_{m}$ & Saturation parameter & 0.12 & $\mathrm{~kg} / \mathrm{m}^{3}$ \\
\hline$k_{1}$ & Inhibition parameter & 0.4545 & $\mathrm{~m}^{3} / \mathrm{kg}$ \\
\hline $\mathrm{Y}$ & Yield coefficient & 0.4 & \\
\hline$x_{2 f}$ & $\begin{array}{l}\text { Substrate } \\
\text { concentration }\end{array}$ & 4 & $\mathrm{~kg} / \mathrm{m}^{3}$ \\
\hline$D$ & Dilution rate & & $\mathrm{h}^{-1}$ \\
\hline
\end{tabular}

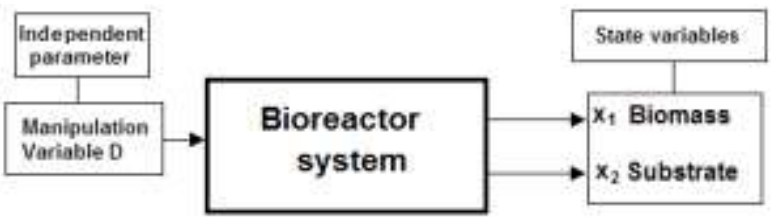

Fig. 4. Block diagram of the bioreactor at open loop. Manipulation variable: dilution rate D (independent variable); state variables: biomass and substrate concentrations (depending on $\mathrm{D}$ value).

By taking D as a model independent parameter (Figure 5) and by varying its value with continuity (Figure 6), it is in fact possible to produce the system bifurcation diagrams for the

state variables $x_{1}$ and $x_{2}[5]$ as shown in Figure 6 and 7, where the continuity diagram, realized with Matcont ${ }^{\circledR}$, is characterized by transcritical bifurcation and limit points.

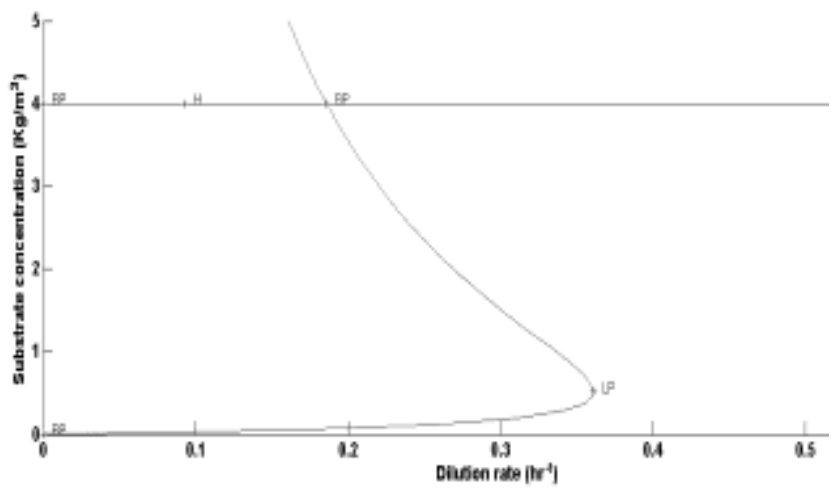

Fig. 5. Bifurcation diagram showing Substrate concentration $\left(\mathrm{kg} / \mathrm{m}^{3}\right)$ vs dilution rate $\left(\mathrm{h}^{-1}\right)$.

Let us consider the uncontrolled bioreactor and assume that the initial condition is the point $A$ on the curve for $S_{f}=4$ $\left(\mathrm{kg} / \mathrm{m}^{3}\right)$ shown in Figure 7, corresponding to the desired substrate concentration value, with the bifurcation parameter $D=0.36 \mathrm{~h}^{-1}$. Now let us suppose that a change occurs in the parameter value $\mathrm{k}_{\mathrm{m}}$ (saturation parameter). As shown in Figures 6-7, the continuity diagram corresponding to the new value of substrate concentration (point B on the top of continuity diagram) is reported. This new operating condition, although stable, is characterized by a high substrate concentration and, consecutively, by a low biomass concentration. Therefore, the new point $\mathrm{B}$ is not a desirable operating condition.

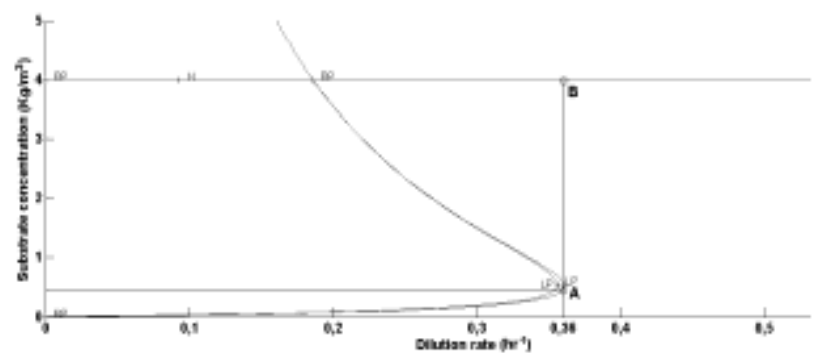

Fig. 6. Bifurcation diagram showing substrate concentration $\left(\mathrm{kg} / \mathrm{m}^{3}\right)$ vs dilution rate $\mathrm{D}\left(\mathrm{h}^{-1}\right)$, for a step in $\mathrm{k}_{\mathrm{m}}$ from 0.12 to $0.13 \mathrm{~kg} / \mathrm{m}^{3}$.

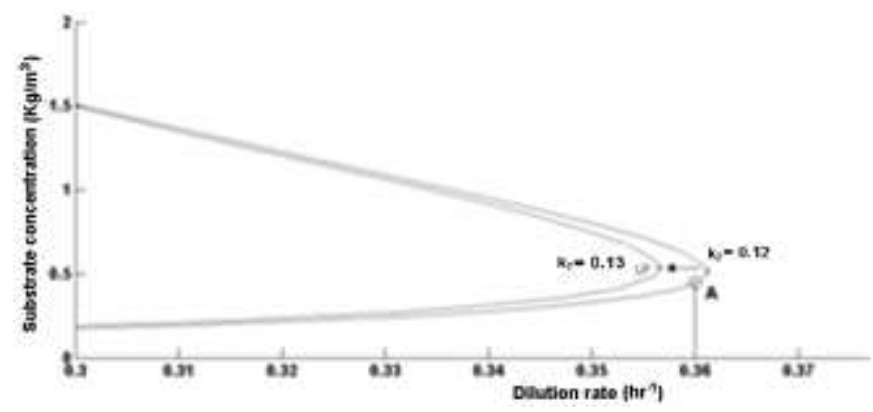

Fig. 7. Zoom of Figure 7 showing the "cuspid" region of substrate concentration $\left(\mathrm{kg} / \mathrm{m}^{3}\right)$ vs dilution rate $\mathrm{D}\left(\mathrm{h}^{-1}\right)$, for a step in $\mathrm{k}_{\mathrm{m}}$ from 0.12 to $0.13 \mathrm{~kg} / \mathrm{m}^{3}$.

In this case, which is easily verified in real situations, the change of a parameter pushed the system towards alternate stable, but undesirable equilibrium points. The same undesirable result may come with a variation of the substrate concentration (disturb). Hence, the adoption of a controller becomes necessary to prevent the system from deviating to these alternate undesirable operating conditions.

\section{FEEDBACK CONTROL}

Controllers of PID type are by far the most widely used in the chemical process industries. Robust PID based indirect-type iterative learning control for batch processes with time-varying uncertainties was developed by Liu et al. [26]; Miccio and Cosenza proposed a control of a distillation column by type- 2 and type-1 fuzzy logic PID controllers [27]; Temperature control in catalytic cracking reactors via a robust PID controller was realized by Aguilar et al. [28]; a PID control of reverse osmosis based desalination process was implemented by Aidhaifallah et al. [29]; more recently, two degree of freedom PID based inferential control of continuous bioreactor for ethanol production was suggested by Pachauri et al. [30]. In feedback control of the bioreactor, the set-point $\left(\mathrm{y}_{\mathrm{sp}}\right)$ is represented by substrate concentration $\left[\mathrm{kg} / \mathrm{m}^{3}\right]$. In the GUI is possible to set simulation time $t$ and initial values of state variable $\mathrm{x}_{1}$ (biomass) and $\mathrm{x}_{2}$ (substrate) in the first panel, and to set substrate feed (disturb) and set-point steps in the second panel. 
Proc. of the Fifth International Conference on Advances in Civil, Structural and Environmental Engineering - ACSEE 2017. Copyright $\odot$ Institute of Research Engineers and Doctors. All rights reserved.

ISBN: 978-1-63248-122-1 doi: 10.15224/ 978-1-63248-122-1-32

In Figure 8 the GUI is shown for bioreactor PID control. It is possible to choose among proportional $(\mathrm{P})$, proportionalintegral (PI) and proportional-integral-derivative (PID) control action, assigning values to controller parameters $\mathrm{Kc}, \tau_{i}$ and $\tau_{D}$, respectively

$m(t)=m_{s}+K_{c} \varepsilon+\frac{K_{c}}{\tau_{i}} \int_{0}^{t} \varepsilon d t+K_{c} \tau_{D} \frac{d \varepsilon}{d t}$

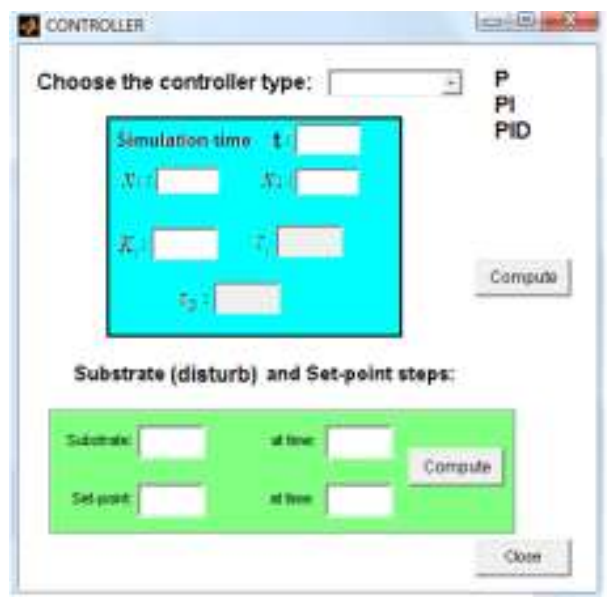

Fig. 8. GUI for bioreactor control.

\section{BIOREACTOR SIMULATION}

Once suitable values are introduced into the appropriate fields (Figure 8), it is possible to start simulations. In Figure 9 the time trajectory of the system substrate concentration for set point tracking (setpoint $=0.18$ ) under a disturbance in the substrate feed concentration (step change from 4 to 5) at time $t$ $=50 \mathrm{~h}$. The program automatically generates three graphs: status variable, variable manipulation, two state variables together as shown in Figures 10, 11 and 12, respectively.

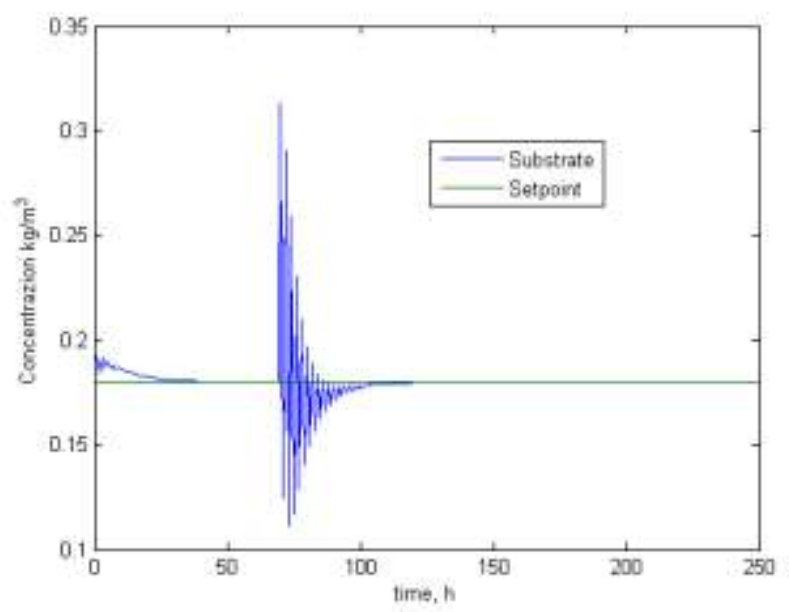

Fig. 9. Time trajectory of the system substrate concentration for set point tracking (set-point $=0.18$ ) under a disturbance in the substrate feed concentration from 4 to 5 at $\mathrm{t}=70 \mathrm{~h}$

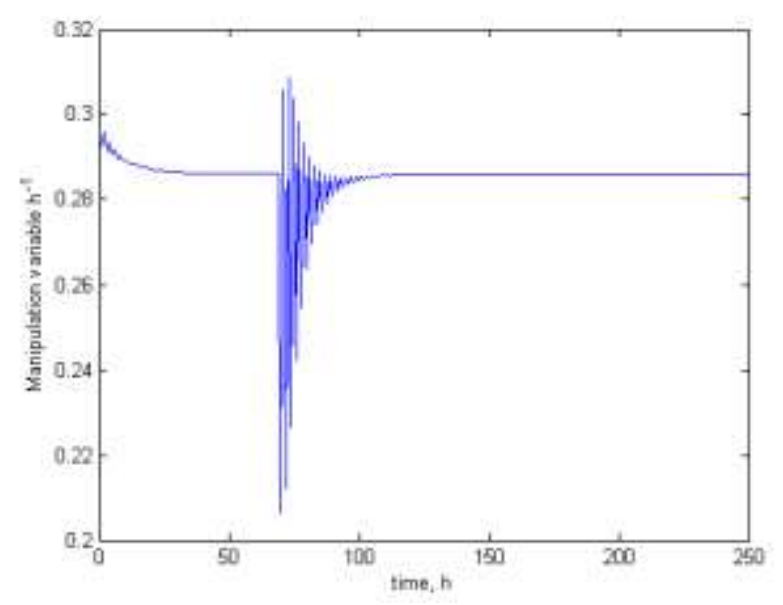

Fig. 10. Time trajectory of the system dilution rate $\mathrm{h}^{-1}$ substrate concentration for set-point tracking (setpoint $=0.18$ ) under a disturbance in the substrate feed concentration from 4 to 5 at $\mathrm{t}=70 \mathrm{~h}$

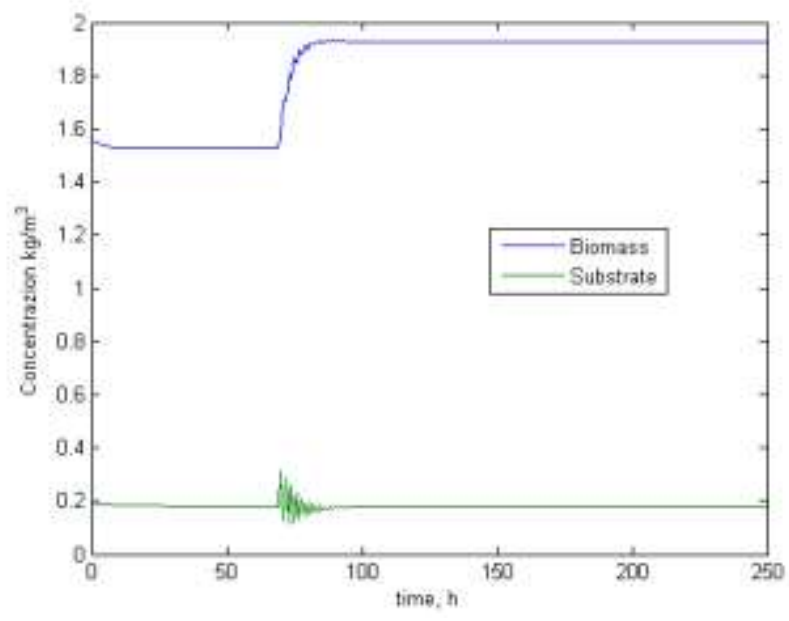

Fig. 11. Time trajectory of the system substrate and biomass concentration for set point tracking (set-point $=0.18$ ) under a disturbance in the substrate feed concentration from 4 to 5 at $t=50 \mathrm{~h}$

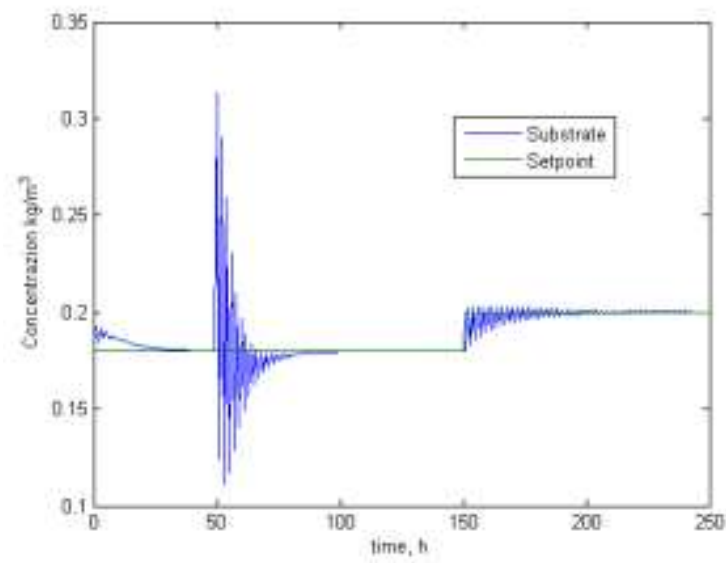

Fig. 12. Time trajectory of the system substrate concentration for set- point tracking under a disturbance in the substrate feed concentration from 4 to 5 at $t=50 \mathrm{~h}$. Set-point value change from 0.18 to 0.2 at time $\mathrm{t}=150 \mathrm{~h}$. 
Proc. of the Fifth International Conference on Advances in Civil, Structural and Environmental Engineering - ACSEE 2017. Copyright $\odot$ Institute of Research Engineers and Doctors. All rights reserved.

ISBN: 978-1-63248-122-1 doi: 10.15224/ 978-1-63248-122-1-32

\section{CONCLUSIONS}

This paper presents a GUI for simulation of dynamics and control of two nonlinear systems: batch reactor and bioreactor. The user can change control parameter values and provide computing without a deepest theoretical knowledge about considered system. This simulation program is therefore very useful for dynamic and control of chemical processes and will be further expanded by the authors including other types of chemical reactors as Fed-batch and CSTR.

\section{REFERENCES}

[1] B.W. Bequette, "Process dynamics: modeling, analysis and simulation", Prentice Hall PTR, 1998.

[2] O. Levenspiel, "Chemical reaction engineering," Third Edition, John Wiley \& Sons, 1999.

[3] W. L. Luyben "Process modeling, simulation and control for chemical engineers", second edition, Mc-Graw Hill, 1996.

[4] W. L. Luyben, "Chemical reactor design and control", John Wiley \& Sons, 2007.

[5] Cosenza B., Miccio M. and Brachi P. "Continuity diagram analysis at open loop and closed loop to improve the operability of a bioreactor", Proceedings of the 14th International Conference on Instrumentation, Measurement, Circuits and Systems (IMCAS15), pp. 105-109; 27-29 Giugno, Salerno, Italia, 2015.

[6] F. Gagnon, A. Desbiens, É. Poulin, P.P. Lapointe-Garant and J.S. Simard, "Nonlinear model predictive control of a batch fluidized bed dryer for pharmaceutical particles", Control Engineering Practice, 64, pp. 88-101, 2017.

[7] A. Holmqvist and F. Magnusson, "Open-loopo optimal control of batch chromatographic separation processes using direct collocation", Journal of Process Control, 46, pp. 55-74, 2016.

[8] Y. Amini, M. Barzegar Gerdroodbary, M. R. Pishvaie, R. Moradi and S. M. Monfared, "Optimal control of batch cooling crystallizers by using genetic algorithm", Case Studies in Thermal Engineering, 8, 2016, pp. 300-310.

[9] S. Wu, Q. Jin, R. Zhang, J. Zhang and F. Gao, "Improved design of constrained model predictive tracking control for batch processes against unknown uncertainties", ISA Transactions, In Press, Corrected Proof, Available online 12 April 2017.

[10] J. Yuan, C. Liu, X. Zhang, J. Xie, E. Feng, H. Yin and Z. Xiu, "Optimal control of a batch fermentation process with nonlinear time-delay and free terminal time and cost sensitivity constraint", Journal of Process Control, 44, 2016, pp. 41-52.

[11] J. Y. Dieulot, "A productivity signal feedback controller for continuous bioreactors" Journal of Process Control, 22, 7, 2012, pp.1318-1324

[12] U Imtiaz, S.S. Jamuar, J.N. Sahu and P.B. Ganesan, "Bioreactor profile control by a nonlinear auto regressive moving average neuro and two degree of freedom PID controllers", Journal of Process Control, 24, 11, 2014, pp. 1761-1777.

[13] L.C. Gerardo, R. Femat and D. Dochain, "An extremum seeking approach via variable-structure control for fed-batch bioreactors with uncertain grow rate", Journal of Process Control, 22, 7, 2012, pp.1318-1324.
[14] J. A. Moreno and J. Alvarez, "On the estimation problem of a class of continuous bioreactors with unknown input, Journal of Process Conteol, 30, 2015, pp. 34-49.

[15] R. Pörtner, O. Platas Barradas, B. Frahm and V.C. Hass, "Advanced Process and Control Strategies for Bioreactors", Current Developments in Biotechnology and Bioengineering, 2017, pp. 463-493.

[16] N. Pachauri, A. Rani and V. Singh, "Bioreactor temperature control using modified fractional order IMC-PID for ethanol production", Chemical Engineering Research and Design, 22, 2017, pp. 97-112.

[17] MatLab 7.0, "Creating Graphical User Interfaces", The MathWorks, Inc.

[18] MatLab 7.0, "The Language of Technical Computing", The MathWorks, Inc.

[19] J. Vojtěšek, P. Dostál and R. Haber, "Simulation and control of a Continuous stirred Tank Reactor", Proc. Of Sixth Portoguese Conference on Automatic Control, Controlo 2004, Faro, Portugal, pp. 315-320, 2004.

[20] J. Vojtěšek, P. Dostál and R. Haber, "From steady-state and dynamic analysis to adaptive control of the CSTR reactor", Proc. Of 19th European Conference on Modelling and Simulation, ESM 2005, Riga, Latvia, pp. 591-598, 2005.

[21] J. Ingham, I. J. Dunn, E. Heinzle, J. E. Přenosil and J. B. Snape, "Chemical Engineering Dynamics. An Introduction to Modeling and Computer Simulation", Second, Completely Revised Edition, VCH Verlagsgesellshaft, Weinheim, 2007.

[22] F. L. Severance, "System Modeling and Simulation: An Introduction". John Wiley \& Sons, 2001.

[23] S. B. Mohamed, B. Boussaid, M. N. Abdelkrim and C. Tahri, "Modeling and simulation of a chemical reactor" Skhira plant case Electrical Sceinces and Technologies in Maghreb (CISTEM), International Conference, 2014.

[24] J. H. Mathews and K. K. Fink, "Numerical Methods Using Matlab", PrenticeHall 2004

V. Bobal, J. Böhm, J. Fessl and J. Machacek, "Digital Selftuning Controllers: Algorithms. Implementation and Applications", Advanced Textbooks in Control and Signal Processing. Springer-Verlag London Limited, 2005.

[26] T. Liu; X. Z. Wang and J. Chen, "Robust PID based indirecttype iterative learning control for batch processes with timevarying uncertainties", Journal of Process Control, 24, 12, 2014, pp. 95-106.

M. Miccio and B. Cosenza, "Control of a distillation column by type-2 and type-1 fuzzy logic PID controllers", Journal of Process Control, In Press, Corrected Proof, 24, 5, 2014, pp. 475-484.

R. Aguilar, A. Poznyak, R. Martinez-guerra and R. MayaYescas, "Temperature control in catalytic cracking reactors via a robust PID controller", Journal od Process Control, 12, 6, 2002, pp. 695-705.

[29] M.M. Aidhaifallah, K.M. Sassi and I.M. Mujtaba, "Pid Control of Reverse Osmosis based Desalination Process", Computer Aided Chemical Engineering, 30, 2012, pp. 812-816.

[30] N. Pachauri, V. Singh and A. Rani, "Two degree of freedom PID based inferential control of continuous bioreacotr for ethanol production, ISA Transactions, 68, 2017, pp. 235-250. 